\title{
In-vitro ovulation of rabbit ovarian follicles isolated after the endogenous gonadotrophin surge
}

\author{
J. Testart, A. Thébault and Brigitte Lefèvre \\ Laboratoire de Physiologie et Psychologie de la Reproduction Humaine, INSERM U.187, \\ Hopital Antoine Béclère, 157 rue de la Porte de Trivaux, 92141 Clamart, France
}

\begin{abstract}
Summary. Follicular rupture was never observed when preovulatory rabbit follicles were isolated from the ovary before the ovulatory gonadotrophin discharge and placed in hormone-free culture for 10-14 h $(n=48)$. However, if the follicles were taken $1 \mathrm{~h}$ post coitum and cultured under the same conditions, 11/24 (45.8\%) ruptured spontaneously. Follicular rupture under these conditions appeared to be chronologically and histologically comparable to that of ovulation in vivo. Culture in the presence of progesterone increased the proportion of follicles ovulating in vitro $(17 / 23=73.9 \%$; $P<0.05$ ). Inhibition in vitro of the synthesis of steroids or prostaglandins suppressed ovulation, although meiotic maturation of the oocyte did take place. These findings indicate that the follicle constitutes an independent entity within the ovary from $1 \mathrm{~h}$ post coitum.
\end{abstract}

\section{Introduction}

While the morphological modifications in the ovarian follicle induced by the preovulatory discharge of gonadotrophins are now well known (Bjersing \& Cajander, 1974; Parr, 1975; Espey, 1978), the sequence of mechanisms leading up to follicular rupture remains obscure. The initiation of the ovulation process by the gonadotrophin surge is a widely accepted phenomenon. In the rabbit the hypophysial discharge of luteinizing hormone ( $\mathrm{LH})$ occurs very soon after coitus, the plasma LH value being significantly increased 20 min post coitum (p.c.) (Dufy-Barbe, Franchimont \& Faure, 1973; Jones, Bain \& Odell, 1976). This discharge of hypophysial hormones brings about important metabolic modifications in the ovary in that the interstitial tissue starts production of 20dihydroprogesterone (Hilliard, Spies \& Sawyer, 1969). In-vivo administration of LH to an oestrous doe leads to an increase in follicular oestrogens (oestrone and oestradiol) at $1 \mathrm{~h} \mathrm{p.c.,} \mathrm{followed} \mathrm{by} \mathrm{a}$ decrease by $4 \mathrm{~h}$ p.c. The concentration of progesterone also increases very rapidly but falls more slowly and persists at a relatively low level up to 6 h p.c. (Patwardhan \& Lanthier, 1976). Prostaglandins (PG) $E$ and $F$ are synthesized by the follicle in appreciable amounts shortly before ovulation (LeMaire, Yang, Behrman \& Marsh, 1973). The follicle wall is modified in the hours after the LH discharge (Bjersing \& Cajander, 1974) and thinning in the apical region facilitates follicular rupture.

Because the sequence of events is difficult to study in vivo, numerous authors have explored the mechanisms of ovulation in vitro, using either the culture of the whole ovary in a culture chamber (Fritz, Chow \& Biggers, 1965; Baranczuk \& Fainstat, 1976), or in-vitro perfusion of the whole ovary (Lambersten, Greenbaum, Wright \& Wallach, 1976; Hamada, Bronson, Wright \& Wallach, 1977; Wallach, Wright \& Hamada, 1978; Janson et al., 1982). These experimental systems have permitted study of the events at the ovarian level that control the triggering of ovulation in vitro. 
The earlier studies enabled ovulation to be obtained as the culmination of a process initiated in vivo. The rupture of about $1 / 3$ of the follicles was achieved with human chorionic gonadotrophin (hCG) present in the medium used for the perfusion of whole ovaries obtained before the ovulatory gonadotrophin discharge (Hamada, Wright \& Wallach, 1979). However, interpretation of experiments on the role of progesterone and prostaglandins is difficult, because substances added to the culture medium and numerous factors may interfere with and modify events in the follicle itself.

The technique described by Ménézo, Gérard \& Thibault (1976) allows a good preservation of bovine follicles cultured in vitro. The system has also been used for the culture of rabbit (Thébault, 1979) and human (Testart, Thébault, Frydman \& Papiernik, 1982) follicles for the study of oocyte maturation. We have now used this technique to study the ovulation process in isolated follicles of the rabbit.

\section{Materials and Methods}

Adult virgin New Zealand does of 3-4 kg (4-6 months of age) were obtained from the Station Centrale de Physiologie, INRA (CNRS, Jouy-en-Josas, France), and used during winter or spring, this period being the most favourable for breeding in rabbits from this source. Only oestrous does, with swollen and violaceous vulvae, were used in experiments. No treatments to induce oestrus or superovulation were used. Does were either mated, or not, and killed by cervical dislocation $1 \mathrm{~h}$ later. Ovaries were excised immediately and transported to the culture laboratory for dissection at ambient temperature.

The technique for the preparation of isolated Graafian follicles in the rabbit has already been described (Thibault \& Gérard, 1973). Follicles were isolated from interstitial tissue by dissection with small forceps. Dissection was continued to the level of the theca interna. Follicles which were haemorrhagic or of extreme size ( $<900$ or $>2000 \mu \mathrm{m}$ ) were discarded. The culture system involved a continual flow of medium and gas (Ménézo et al., 1976), and consisted of three principal components: medium reservoir, culture chamber and peristaltic pump (see Text-fig. 1). Follicles were placed in groups of 10-15 in each chamber within 15-45 min of killing the does. Media used were Medium 199 with Hepes and L-glutamine (Gibco, Paisley, U.K.) for dissection, and Medium $\mathbf{B}_{2}$ (Ménézo, 1976; Api-system, La-Balme-Les-Grottes, France) for culture. A gas mixture of $57 \%$ $\mathrm{O}_{2}+5 \% \mathrm{CO}_{2}+38 \% \mathrm{~N}_{2}$ was used for the cultures, which were continued for $10-14 \mathrm{~h}$. The follicles were examined with a dissecting microscope.

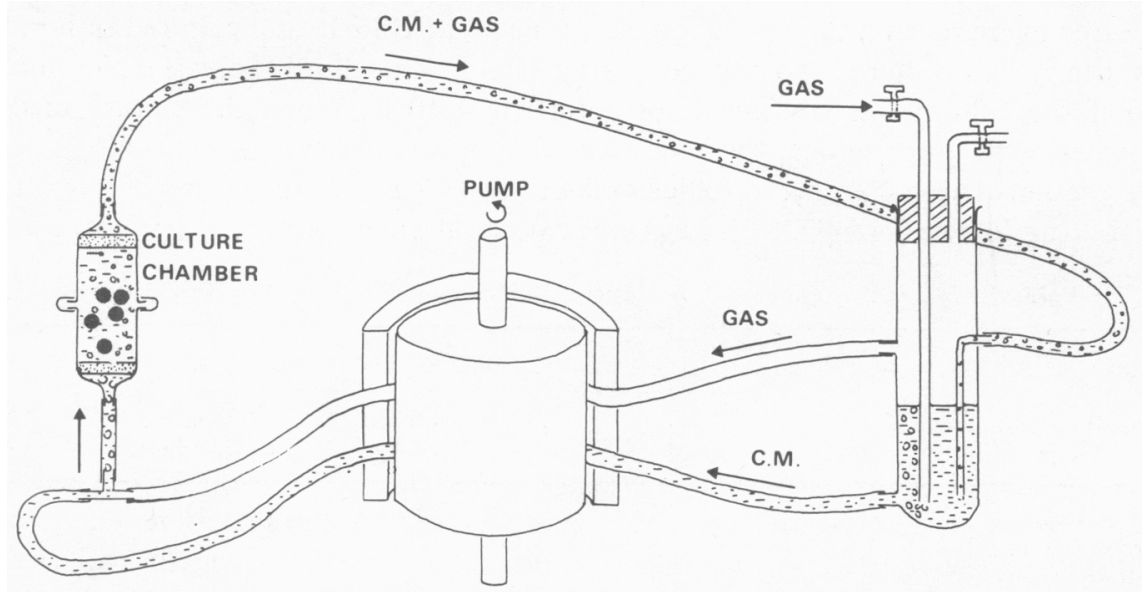

Text-fig. 1. Schematic representation of the culture system with continuously circulating medium and gas (adapted from Ménézo et al., 1976). C.M. = culture medium; gas $=\mathrm{O}_{2}$ $(57 \%), \mathrm{CO}_{2}(5 \%)$ and $\mathrm{N}_{2}(38 \%) ; O$, isolated follicles inside the culture chamber. 
Progesterone (Roussel, Paris) was added at the start of the culture period at a final concentration of $10 \mu \mathrm{g} / \mathrm{ml}$, and aminoglutethimide (Ciba Geigy, Rueil-Malmaison, France) was used at $10^{-3} \mathrm{M}$. Indomethacin (Merck, Darmstadt, Germany) was added to the perfusion circuit at $7 \mathrm{~h}$ p.c. at $1 \mathrm{mg} / \mathrm{ml}$. In 3 does indomethacin was injected intramuscularly at $5 \mathrm{mg} / \mathrm{kg}$ body weight at $15 \mathrm{~min}$ p.c.

Progesterone concentrations in the culture media were determined according to the method of Thibier \& Saumande (1975). The lack of cross-reactions $(<1 \%)$ with other steroids confirmed the specificity of this method. The limit of sensitivity was estimated as $0.11 \mathrm{ng} / \mathrm{ml}$. The intra-assay coefficient of variation was $9 \%$. Mean blank value was $0.06 \pm 0.07 \mathrm{ng} / \mathrm{ml}$ and the recovery value was $80.4 \pm 1 \cdot 2 \%$. At the end of the culture period the follicles were fixed in Bouin-Hollande's fluid and processed routinely for histological examination in $10 \mu \mathrm{m}$ serial sections. The appearance of the membrana granulosa indicated the condition of the follicle after culture. Resumption of meiosis by the oocytes was also evaluated, as was the state of the follicle wall in the rupture zone.

Differences between proportions of ovulating follicles were examined by $\chi^{2}$ tests.

\section{Results}

\section{Description of follicular rupture}

After incubation for 10-14 h, freshly ruptured follicles were found in the culture chambers. The macroscopic appearance of the rupture zones was comparable to that observed in the ovary in vivo. The follicle apex was shaped like a truncated cone from which emerged the cumulus mass containing the oocyte (Pl. 1, Fig. 2). The cumulus was very dissociated, and histological examination showed the oocyte to have resumed meiosis (P1. 1, Figs 1 \& 2). About half of the unruptured follicles had an atretic membrana granulosa.

The position of the point of rupture was variable. Assuming that the original orientation of the follicle within the ovary could be determined by the presence of shreds of ovarian epithelium remaining on the follicle wall, it could be ascertained that rupture did not always occur at the original external pole of the follicle. Flattening of the epithelial cells and oedema in the adjacent epithelium were always present in this zone.

\section{Factors affecting in-vitro ovulation}

No ovulations were recorded in the 48 follicles taken before the $\mathrm{LH}$ peak and cultured in hormone-free medium. In a further 24 follicles, isolated at $1 \mathrm{~h}$ p.c. and cultured in hormone-free medium, nearly half ruptured spontaneously after $10-14 \mathrm{~h}$ in culture (Table 1 ). No more follicles ruptured if the culture was continued for a further 4-10 h. When the culture medium was supplemented with progesterone, the level of ovulation was increased (see Table 1).

The secretion of progesterone, by follicles taken $1.5-4.0 \mathrm{~h}$ p.c., in the hormone-free cultures was $10.09 \pm 1.26 \mathrm{ng} /$ follicle ( 24 follicles in 2 cultures). When aminoglutethimide $\left(10^{-3} \mathrm{M}\right)$ was added to

Table 1. In-vitro ovulation of rabbit follicles cultured from $1.5 \mathrm{~h}$ post coitum

\begin{tabular}{lcccc}
\hline \multirow{2}{*}{$\begin{array}{c}\text { Culture medium supplemented } \\
\text { with }\end{array}$} & Donor rabbits & $\begin{array}{c}\text { Cultured } \\
\text { follicles }\end{array}$ & $\begin{array}{c}\text { Ovulating } \\
\text { follicles }\end{array}$ & $\begin{array}{c}\% \text { ovulating } \\
\text { follicles }\end{array}$ \\
\cline { 2 - 5 } & 5 & 24 & 11 & $45 \cdot 8^{* \dagger}$ \\
Nothing (control) & 5 & 23 & 17 & $73 \cdot 9^{*}$ \\
Progesterone $(10 \mu \mathrm{g} / \mathrm{ml})$ & 4 & 25 & 0 & $0 \dagger$ \\
Aminoglutethimide $\left(10^{-3} \mathrm{M}\right)$ & 3 & 14 & 0 & 0 \\
Indomethacin $(1 \mu \mathrm{g} / \mathrm{ml})$ & & $P$ & $0.05 ;+P$
\end{tabular}

${ }^{*} P=0.05 ; \nmid P<0.001$. 
the medium, progesterone secretion was only $2.34 \pm 0.96 \mathrm{ng} /$ follicle (46 follicles in 3 cultures; $P<0 \cdot 01$ ). Under these conditions none of the 25 follicles cultured for up to $18-24 \mathrm{~h} p . c$. ruptured (Table 1). If the final synthesis of prostaglandins was inhibited in the cultured follicles by the addition of indomethacin to the medium at $7 \mathrm{~h}$ p.c., follicular rupture was totally inhibited (Table 1). Similarly, the administration of indomethacin in vivo at $15 \mathrm{~min}$ p.c. also inhibited the ovulation in vitro of 13 follicles isolated 45 min later.

In those follicles in which steroid synthesis was inhibited by aminoglutethimide, the oocytes resumed meiosis up to metaphase II. It has been possible to fertilize 27 of 34 oocytes matured in such conditions (Thébault, 1979).

\section{Discussion}

Follicular rupture in vitro resembles ovulation in vivo. The supervening conditions of follicular rupture (endocrine requirements, chronology) and the morphological appearance of the ruptured follicles would seem to indicate a similar physiological phenomenon. Chance rupture, or rupture due to trauma induced by the culture system, may be disregarded since those follicles that were not exposed to $\mathrm{LH}$ in vivo did not ovulate.

The time of follicular rupture was also close to that of spontaneous ovulation (i.e. $11 \mathrm{~h}$ p.c. in the strain of rabbits used). Furthermore, follicles unruptured at $14 \mathrm{~h}$ did not rupture if culture was continued until 18-24 h. The edges of the rupture zone also closely resembled those seen for in-vivo ovulations (Bjersing \& Cajander, 1974).

Some of the follicles never ovulated. About $50 \%$ of these follicles, often of large size, were seen to be atretic. This atresia had probably begun before culture of the follicles, although this cannot be stated with certainty due to the difficulty of selection using only the macroscopic appearance of the follicles. The selection of good quality follicles was favoured by the choice of season for the experiments, and also by the absence of any ovarian stimulation. Furthermore, when the follicles did ovulate, their granulosa cell masses were seen to be well preserved, and the same culture system has previously enabled the in-vivo fertilization of $50 / 85(58 \%)$ oocytes matured in their follicles in vitro (Thébault, 1979). The proportion of follicles ovulating, particularly after addition of progesterone to the medium $(74 \%)$, is appreciably higher than that previously obtained after the culture of whole ovaries (Hamada et al., 1979), even though in this latter study only the terminal phase of ovulation was achieved in vitro.

The present results also show that the ovarian musculature is not indispensible for follicular rupture. Even if ovarian contractions do facilitate rupture (Espey, 1978), the latter may still also occur in the absence of any such contractile activity. Doubtless there are contractions of the follicle itself, as shown by the pleated appearance of the granulosa in many of the control follicles.

In the rat, ovarian progesterone produced during the preovulatory period, or the administration of progesterone, may lead to ovulation in vivo (Kobayashi, Hara \& Miyake, 1973; Takahashi, Ford,

\section{PLATE 1}

Histological sections of cultured rabbit follicles.

Fig. 1. After $10 \mathrm{~h}$ in culture the oocyte is at the metaphase II stage of meiosis. Notice expanded cumulus and pleated granulosa wall. $\times 50$.

Fig. 2. The follicle apex is shaped like a truncated cone from which emerges the cumulus mass containing the oocyte. Arrow: first polar body. $\times 80$.

Fig. 3. Follicle ovulation after $12 \mathrm{~h}$ in culture. $\times 40$.

Fig. 4. Flattening of the epithelial cells (ep.) and oedema (oed.) near the follicle wall. th $=$ theca $; \mathrm{gr}=$ granulosa. $\times 180$. 

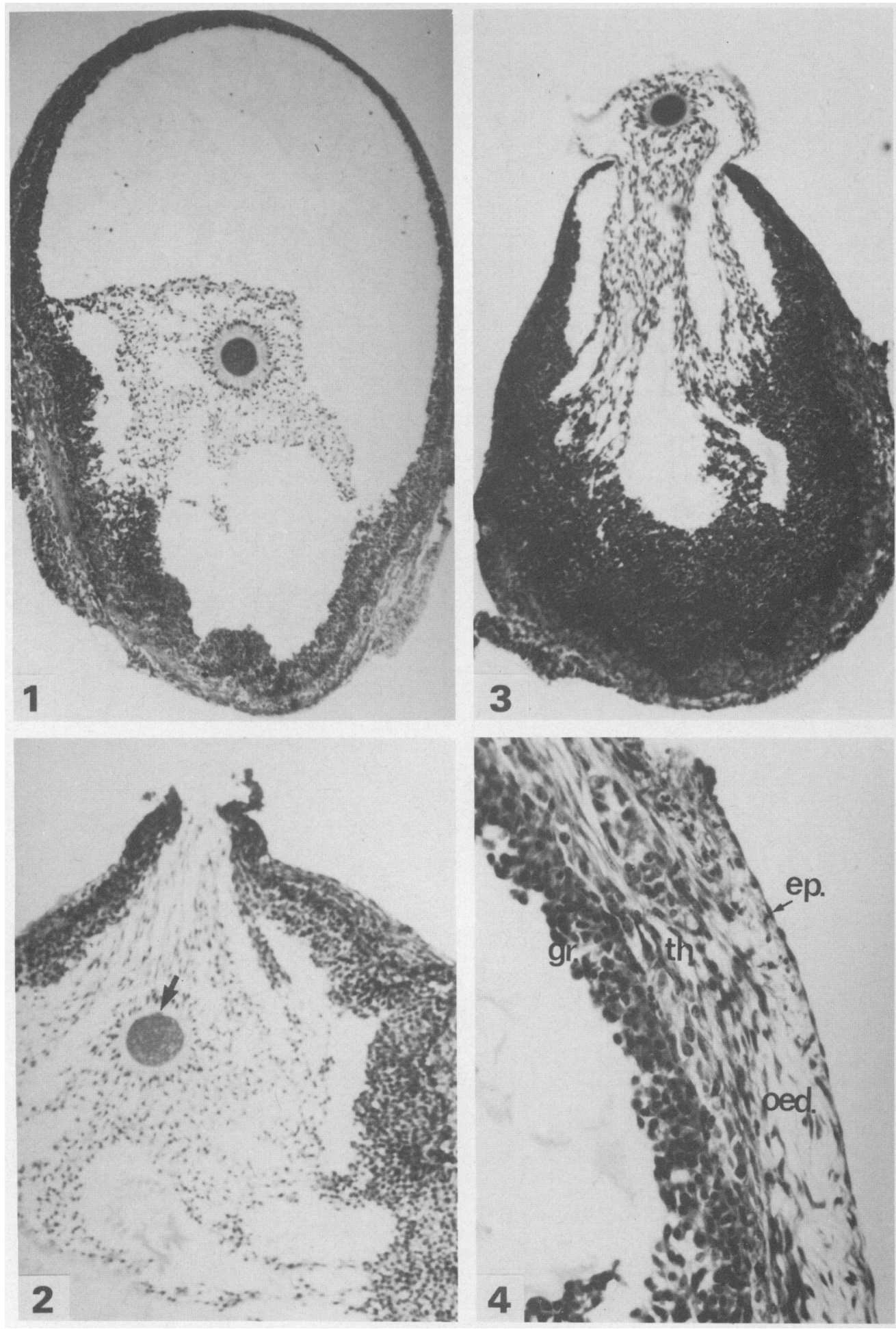

(Facing p. 416) 
Yoshinaga \& Greep, 1974; Sridharan, Meyer \& Karavolas, 1974). However, in these in-vivo experiments it is difficult to determine whether the effect is due to a central mode of action of the progesterone, or to a local action at the level of the ovary. In the hamster, Baranczuk \& Fainstat (1976) have shown in vitro that progesterone has a local effect upon the final stage of ovulation. Androgens may also play a role since antiserum to testosterone administered in vivo greatly reduces the number of ovulations (Mōri, Suzuki, Nishimura \& Kambegawa, 1977). In this last experiment only progesterone was assayed to demonstrate the effect of aminoglutethimide, but Behrman, Armstrong \& Greep (1970) have shown an inhibitory effect on the synthesis of all steroids. This reduction in the production of steroids by follicles in vitro suppressed follicular rupture. In the present study it has been shown that the addition of progesterone to the medium significantly increases the number of ovulations obtained in vitro, confirming the results of Hamada et al. (1979). However, on isolated follicles, the effect was much clearer $(45.8 \%$ compared with $73.9 \%, P=0.05)$, undoubtedly due to a direct action of the progesterone on the follicles.

The existence of a role for prostaglandins in regulating the mechanism of ovulation is based on studies in which PG synthesis was inhibited by indomethacin. Administration of indomethacin at the appropriate time blocks ovulation in the rabbit (O'Grady, Caldwell, Auletta \& Speroff, 1972; Grinwich, Kennedy \& Armstrong, 1972), as well as in numerous other species. Prostaglandins act directly upon the follicles, as shown when applied directly to the follicles on the one hand, and by the very rapid increase in their concentrations within the follicle on the other (LeMaire et al., 1973). Inhibition of follicular rupture in vitro by indomethacin can be obtained under two conditions: either precociously by its injection in vivo before isolation of the follicles, or later by its addition to the culture medium in vitro. In the former case, indomethacin may have both an immediate action on the ovarian prostaglandins produced under the stimulus of $\mathrm{LH}$, and also a delayed action by virtue of its persistence. In the latter case, inhibition is still possible if indomethacin is added to the culture at $7 \mathrm{~h}$ p.c., but it is a direct effect upon the follicle itself, since it is being cultured in isolation.

In conclusion, the technique of culturing isolated follicles in vitro enables follicular rupture to be obtained. The phenomenon occurring in vitro is equivalent to that in vivo: morphological and chronological aspects, as well as the actions of inducers and inhibitors, all appear to be identical. The system is therefore useful to study the respective roles of steroids, prostaglandins, and other substances, in the process of ovulation.

We thank Mr Bruno Lassalle for help with the preparation of specimens for histology and $\mathrm{Mr}$ Bernard Moret from the Centre National de Recherches Zootechniques (Jouy-en-Josas 78350, France) for supplying oestrous does.

\section{References}

Baranczuk, R.J. \& Fainstat, T. (1976) In-vitro ovulation from adult hamster ovary. Am. J. Obstet. Gynec. 124, $517-522$.

Behrman, H.R., Armstrong, D.T. \& Greep, R.O. (1970) Studies on the rapid cholesterol depleting and steroidogenic actions of luteinizing hormone in the rat ovary: effects of aminoglutethimide phosphate. Can. J. Biochem. 48, 881-884.

Bjersing, L. \& Cajander, S. (1974) Ovulation and the mechanism of follicle rupture. I. Light microscopic changes in rabbit ovarian follicle prior to induced ovulation. Cell. Tissue Res. 149, 287-300.

Dufy-Barbe, L., Franchimont, P. \& Faure, J.M.A. (1973) Time courses of $\mathrm{LH}$ and FSH release after mating in the female rabbit. Endocrinology 92, 1318-1321.

Espey, L.L. (1978) Ovarian contractility and its relationship to ovulation: a review. Biol. Reprod. 14, 540-551.
Fritz, H.I., Chow, K. \& Biggers, J.D. (1965) Ovulation from whole ovaries of mice in organ culture. J. Cell Biol. 27, 31 A, Abstr.

Grinwich, D.L., Kennedy, T.G. \& Armstrong, D.T. (1972) Dissociation of ovulatory and steroidogenic actions of luteinizing hormone in rabbits with indomethacin, an inhibitor of prostaglandin synthesis. Prostaglandins 1, 89-96.

Hamada, Y., Bronson, R.A., Wright, K.A. \& Wallach, E.E. (1977) Ovulation in perfused rabbit ovary: the influence of prostaglandins and prostaglandins inhibitors. Biol. Reprod. 17, 58-63.

Hamada, Y., Wright, K.H. \& Wallach, E.E. (1979) The effects of progesterone and human chorionic gonadotropin on ovulation in the in vitro perfused rabbit ovary. Fert. Steril. 32, 335-339.

Hilliard, J., Spies, H. \& Sawyer, C.H. (1969) Hormonal 
factors regulating ovarian cholesterol mobilization and progestin secretion in intact and hypophysectomized rabbits. In The Gonads, pp. 55-92. Ed. K. W. McKerns. Appleton Century Crofts, New York.

Janson, P.O., LeMaire, W.J., Källfelt, B., Homes, P.V., Cajander, S., Bjersing, L., Wigvist, N. \& Ahrén, K. (1982) The study of ovulation in the isolated perfused rabbit ovary. I. Methodology and pattern of steroidogenesis. Biol. Reprod. 26, 456-465.

Jones, E.E., Bain, J.B. \& Odell, W.D. (1976) Post coital luteinizing hormone release in male and female rabbits as determined by radioimmunoassay. Fert. Steril. 27, 848-852.

Kobayashi, F., Hara, K. \& Miyake, T. (1973) Facilitation by progesterone of ovulating hormone release in sodium pentobarbital-blocked proestrus rats. Endocr. jap. 20, 175-180.

Lambersten, C.J., Greenbaum, D.F., Wright, K.H. \& Wallach, E.E. (1976) In-vitro studies of ovulation in the perfused rabbit ovary. Fert. Steril. 27, 178-187.

LeMaire, W.J., Yang, N.S.T., Behrman, H.N. \& Marsh, J.M. (1973) Preovulatory changes in the concentration of prostaglandins in rabbit Graafian follicles. Prostaglandins 3, 367-376.

Ménézo, Y. (1976) Milieu synthétique pour la survie et la maturation des gamètes et pour la culture de l'oeuf fécondé. C. r. hebd. Séanc. Acad. Sci., Paris D 282, 1967-1970.

Ménézo, Y., Gérard, M. \& Thibault, C. (1976) Culture du follicule de De Graaf de bovin dans un système à courant liquide et gazeux continu. C. r. hebd. Séanc. Acad. Sci., Paris D 283, 1309-1311.

Mōri, T., Suzuki, A., Nishimura, T. \& Kambegawa, A. (1977) Evidence for androgen participation in induced ovulation in immature rats. Endocrinology 101, 623-624.

O'Grady, J.P., Caldwell, B.V., Auletta, E.J. \& Sperof, F. (1972) The effects of an inhibitor of prostaglandin synthesis (indomethacin) on ovulation, pregnancy, and pseudopregnancy in the rabbit. Prostaglandins 1, 97-106.

Parr, E.L. (1975) Rupture of ovarian follicles at ovulation. J. Reprod. Fert., Suppl. 22, 1-22.

Patwardhan, V.V. \& Lanthier, A. (1976) Effect of an ovulatory dose of luteinizing hormone on the concentration of oestrone, oestradiol and progesterone in rabbit ovarian follicles. Acta endocr., Copenh. 82, 792-800.

Sridharan, B.N., Meyer, R.K. \& Karavolas, H.J. (1974) Induction of ovulation by pregn-5-ene-3,20-dione and progesterone in immature rats treated with PMSG and phenobarbital. J. Reprod. Fert. 39, 259-266.

Takahashi, M., Ford, J., Yoshinaga, K. \& Greep, R.O. (1974) Induction of ovulation in hypophysectomized rats by progesterone. Endocrinology 95, 1322-1326.

Testart, J., Thébault, A., Frydman, R. \& Papiernik, E. (1982) Oocyte and cumulus oophorus changes inside the human follicle cultured with gonadotrophins. In In-vitro Fertilization and Embryo Transfer, pp. 181198. Eds E. S. E. Hafez \& K. Semm. MTP, Lancaster.

Thébault, A. (1979) Maturation ovocytaire et stéroidogénèse dans le follicule ovarien de la lapine, in vitro. Ph.D. thesis, Université Paris VI.

Thibault, C. \& Gérard, M. (1973) Cytoplasmic and nuclear maturation of rabbit oocytes in vitro. Annls Biol. anim. Biochim. Biophys. 13, 145-156.

Thibier, M. \& Saumande, J. (1975) Estradiol-17 $\beta$, progesterone and 17-hydroxyprogesterone concentration in jugular venous plasma in cows prior to and during estrus. J. Steroid Biochem. 6, 1433-1437.

Wallach, E.E., Wright, K.H. \& Hamada, Y. (1978) Investigation of mammalian ovulation with an in vitro perfused rabbit ovary preparation. $A m$. $J$. Obstet. Gynec. 132, 728-738.

Received 26 November 1982 